\title{
Breast cancer survivors' recollection of their illness and therapy seven years after enrolment into a randomised controlled clinical trial
}

Patricia Lindberg ${ }^{1 *}$, Michael Koller ${ }^{2}$, Brunhilde Steinger ${ }^{1}$, Wilfried Lorenz ${ }^{1 \wedge}$, Jeremy C. Wyatt ${ }^{3}$, Elisabeth C. Inwald ${ }^{4}$ and Monika Klinkhammer-Schalke'

\begin{abstract}
Background: Little is known about the subjective experience of breast cancer survivors after primary treatment. However, these experiences are important because they shape their communication about their illness in everyday life, usage and acceptance of healthcare, and expectations of new generations of patients. The present study investigated this topic by combining qualitative and quantitative methods.

Methods: Breast cancer survivors in Bavaria, Germany were mailed a questionnaire up to seven years after enrolment into a randomised controlled clinical trial and start of their therapy. This enquired about their worst experiences during the breast cancer episode, positive aspects of the illness and any advice they would give to newly diagnosed patients. A category system for themes was systematically created and answers were categorised by two independent raters. Frequencies of key categories were then quantitatively analysed using descriptive statistics. In addition, local treating physicians gave their opinion on the response categories chosen by their patients.

Results: 133 (80 \%) of 166 eligible patients who survived up to seven years returned the questionnaire. The most prominent worst experience reported by survivors was psychological distress (i.e. anxiety, uncertainty; prevalence $38 \%$ ) followed by chemotherapy (25\%), and cancer diagnosis (18\%). Positive aspects of the illness were reported by $48 \%$ with the most frequent including change in life priorities (50\%) and social support (22\%). The most frequent advice survivors gave was fighting spirit (i.e. think positive, never give up; prevalence $42 \%$ ). Overall, physicians' estimates of the frequency of these responses corresponded well with survivors' answers.

Conclusions: Although physicians' understanding of breast cancer patients was good, psychological distress and chemotherapy-related side effects were remembered as particularly burdensome by a substantial part of survivors. On the one hand, patients' quality of life needs to be assessed repeatedly during medical follow-up to identify such specific complaints also including specific recommendations to the physician for targeted psychosocial and medical support. On the other hand the advices and positive aspects of the disease, reported by the survivors, can be used to promote positive ways of coping with the illness.
\end{abstract}

Keywords: Breast cancer, Survivorship, Qualitative analysis, Quality of life, Patient-physician agreement, Complex intervention

\footnotetext{
*Correspondence: patricia.lindberg@ukr.de

Deceased

'Tumor Center Regensburg e.V., An-Institute of the University of Regensburg,

Regensburg, Germany

Full list of author information is available at the end of the article
} 


\section{Background}

During the last years there has been growing interest regarding survivorship in breast cancer patients. One reason is the increasing number of long-term survivors due to improved screening and earlier treatment. A bulk of studies has investigated quality of life in long-term breast cancer survivors [1-5]. Overall it has been shown that patients recover from most impairments during the first year of illness [6-9] resulting in a long-term quality of life that is comparable to the general female population in most dimensions $[1,5]$. Nonetheless, some persistent specific complaints have been identified in breast cancer survivors, such as arm symptoms, reduced sexual functioning, or fatigue $[3,5,10]$. Besides, fear of recurrence is often prevalent and negatively affects well-being $[1,10,11]$. A systematic review [12] of ten studies on breast cancer survivors' quality of life concluded that good quality of life more than five years after diagnosis was associated with the absence of chemotherapy or comorbidities, high income, and sufficient levels of social support. However, many breast cancer survivors also experienced persistent specific complaints, such as arm symptoms or sexual problems. Furthermore, numerous more recent studies investigated various therapeutic approaches (stress reduction, exercise, counselling, spiritual therapy) for improvement of quality of life in randomised controlled trials [13-16].

These studies investigating long-term quality of life of cancer survivors predominantly use standardised measures. To date, there exists no established questionnaire that focuses specifically on the quality of life of survivors. Therefore, most studies use instruments initially developed for monitoring the course of diagnosis and treatment, such as EORTC QLQ-C30 [17] or FACT-G [18]. Although these instruments have their merits, it is possible that they omit aspects of the cancer experience that are important for survivors. Qualitative research is one way to resolve this, as this allows us to explore the survivor perspective and elicit a wider spectrum of answers than closed-ended quality of life questions. Thus issues can be detected that are omitted from standardised questionnaires [19]. This may elicit new hypotheses that can be analysed quantitatively. A good example of this approach is the study by Lauver et al. [20] that combined quantitative and qualitative measures to explore stressors after the end of primary therapies. By using open-ended qualitative questions they identified "dealing with uncertainties" as a stressor which would have been otherwise overlooked.

Another relatively unexplored field is cancer survivors' personal evaluation of their illness course [21]. The meaning of the cancer experience to 58 longterm survivors was investigated by Foley et al. [22] using interviews more than five years post-diagnosis.
They demonstrated that most survivors reported either little impact of cancer or even a positive longterm influence on their lives, such as more inner strength and a greater appreciation of life. This kind of personal growth was associated with a better quality of life.

The starting point of this research was the patient perspective which is communicated in their everyday life to family, friends, other patients, and physicians and might influence women's attitude toward the illness as well as their use and acceptance of health services, support services and alternative therapies. More specifically, the aim of the present study was to examine the recollections of breast cancer survivors seven years after diagnosis regarding their (1) worst experiences during the illness, (2) potential positive aspects of the disease, and (3) the advice they would give to fellow patients. Another aim was to investigate if these responses of patients correspond with the opinion of their physicians regarding breast cancer survivors' worst and most positive experiences and advices (4).

\section{Methods \\ Sample}

The study sample consisted of 200 female primary breast cancer patients who had participated in a randomised controlled clinical trial investigating the use of standardised quality of life diagnostics and related therapies to improve patients' subjective recovery [23]. All participants had been surgically treated between 2004 and 2006 in one of five participating certified breast cancer centres in Bavaria, Germany. To achieve high external validity, the trial inclusion criteria had no restrictions regarding disease stage or age [24]. Details about the theoretical background, method, and results of this complex intervention have been previously described [23, 25-27].

Follow-up of survivors was conducted up to seven years after breast cancer diagnosis in August and December 2012 (mean time since surgery 84 months; range 73-93 months). The term "survivor" is here used as five year survival of the cancer diagnosis, a criterion commonly accepted in cancer statistics $[28,29]$. Therefore we supposed that the chosen time point for follow-up was adequate to investigate the perspective of "real" long-term survivors.

\section{Design}

A cross-sectional design was used for the present study. This study constitutes Part IV (long-term implementation) of a large scale complex intervention project [30] on the routine use of quality of life data in oncological practice. Part I [26], II [27], and III [23] have already been published. Ethical approval had been obtained from the local university ethics committee (University of 
Regensburg, 03/197) and patients had given their informed consent. In August 2012 all eligible women were mailed a package of questionnaires supplemented by a stamped return envelope and a cover letter informing them about content and aims of the study. Patients who did not respond within six weeks received one reminder by telephone. Those who could not be contacted by phone were mailed a reminder with the questionnaire package [31]. There were no financial or other incentives to respond.

\section{Measures/instruments \\ Demographic and clinical variables}

In this survey the following data were collected: age, marital status, number of children, education level, and employment status. Prognostic stage, type of surgical procedure, and adjuvant/ neo-adjuvant therapy were obtained from the original record of the randomised trial.

\section{Qualitative questionnaire}

The survivor questionnaire consisted of one page with three qualitative, open-ended questions:

(1) "Which was the worst experience regarding your cancer disease?"

(2) "Have there also been positive aspects according to the illness?"

(3) "Which advice would you give newly diagnosed breast cancer patients to cope with the disease?"

This questionnaire had been tested beforehand in a pilot survey with breast cancer survivors who were not part of the randomised trial cohort and thus did not take part in the present survivorship study. Twelve women with an earlier diagnosis of breast cancer participated in the pilot study (mean time since diagnosis: 55.5 months, range 11-84 months) with a mean age of 58 years (s.d. \pm 7.5 , range $45-69$ years). Pilot participants evaluated the qualitative questions as clearly formulated and easy to understand. No woman perceived the content of the qualitative questionnaire as unpleasant. Only one participant noted that the question asking for an advice for newly diagnosed patients was difficult to answer. Overall, the qualitative questionnaire was highly accepted and revealed useful insights into their illness so there was no need for modification.

\section{Developing a category system for qualitative answers}

To analyse the qualitative data, categories were generated by inductive analysis encompassing all prominent and relevant issues regarding the worst and positive experiences and advice for fellow patients (see Fig. 1). Because little is known about the investigated research field, candidate themes were derived from the data

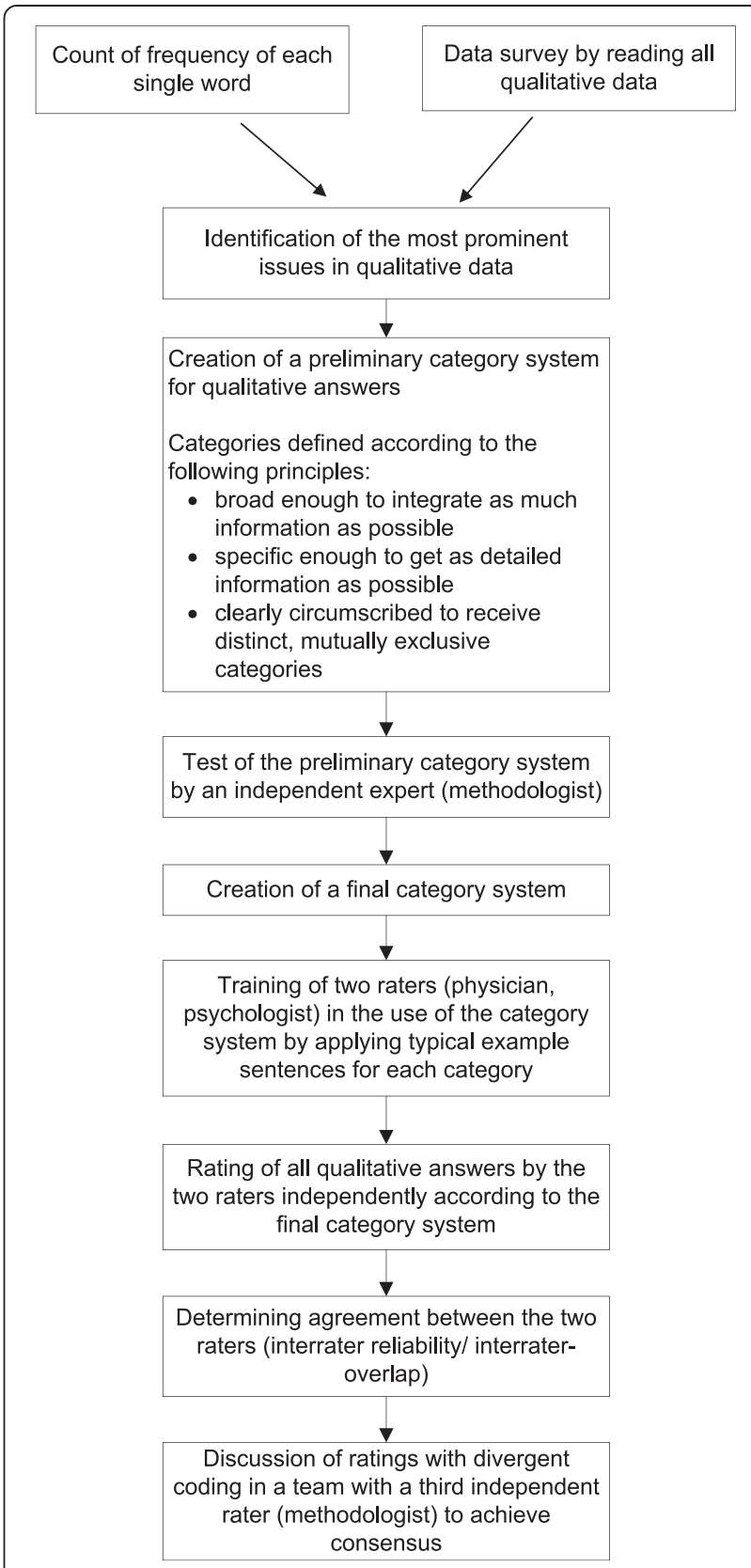

Fig. 1 Sequence of each step in the qualitative data analysis process in the survivor study

instead of using a predefined category system [32]. This was done independently by two investigators. Consensus was reached by discussion.

To quantify the proportion of responders mentioning each finding, answers were transferred to an electronic database (Microsoft Access 2010). In the first step, data were inspected using two different strategies: (1) using a word-by-word analysis, frequency of each word individually was counted using a computer program. Through this, issues which were commonly 
addressed by participants could be objectively identified, based on "Linguistic Inquiry and Word Count" (LIWC) by Pennebaker et al. [33]); (2) using a more holistic approach, the answers from all participants were read to become familiar with the data and their context. On the basis of (1) and (2) the most prominent issues in women's answers were identified and transferred to a preliminary category system, considering the following criteria: each category should be broad enough to include as much information as possible, so that a reasonable picture of women's answers could be given. At the same time categories were designed to be as specific as possible, to include meaningful information regarding content of the data. Furthermore, categories were clearly circumscribed and mutually exclusive so that data could be only assigned to one category.

The final category system contained 11 different categories for worst experience, 6 categories for positive aspects and 13 categories for advice for fellow patients (see Table 1). To facilitate the practical use of this coding system, each category was illustrated with a short description and text examples that resembled but were not identical to the patients' original answers. Two raters (a physician and a psychologist) were trained in this category system and were then instructed to categorise all patient responses independently [34]. Some answers contained multiple statements belonging to more than one category. Those had to be divided into single issues and classified in different categories. Finally, both raters met with the third independent expert (methodologist) to discuss divergent ratings until consensus was achieved [35].

\section{Survey of coordinating practitioners}

Following completion of data analysis of the patient survey, a survey was conducted with those physicians who had taken care of the patients' treatment and follow-up during the randomised trial [23]. Thus, the physicians were familiar with quality of life issues and would have managed one or more patients who were participating in the survivorship study. The aim of this survey was to compare physicians' opinions regarding worst and most positive experiences of breast cancer survivors with the survivors' actual perspective. A total of 50 eligible physicians were mailed a five-page questionnaire supplemented by a stamped return envelope and a letter explaining the study aim. The questionnaire referred to the three qualitative questions that were the focus of the patient survey (worst experience, positive experience, advice to fellow patients). After presenting the five most frequent categories from the patient survey for each of the three qualitative questions, the physicians' task was to arrange the categories according to their expectation of the survivors' response frequency, from "1" (most common answer) to "5" (less common answer). All the categories and category descriptions were taken from our analysis of the patient questionnaire data.

\section{Statistical analysis}

Agreement between the two raters of categories was analysed using intercoder percent agreement and Cohen's kappa to account for random agreement. Response categories were analysed quantitatively in a descriptive manner and reported as frequencies and proportions. For physicians' ratings, means were calculated for each category as well as the percentage of each category ranked as number "1". All data were analysed using SPSS software version 20 .

\section{Results}

\section{Participant characteristics}

Of the 200 patients enrolled into the randomised study, three patients refused further participation and 31 had died at the time of the present study. Thus, 166 patients were eligible and 133 returned the questionnaire, a response rate of $80 \%$ (Fig. 2).

The mean age of participants at long-term follow-up was 64.2 years (s.d. \pm 10.8 ) and average interval since surgery was 84.8 months (s.d. \pm 5.6). Further demographic and medical characteristics of participants are reported in Table 2.

Respondents $(n=133)$ did not differ from nonrespondents $(n=33)$ regarding age, time since surgery, stage, type of surgery, or recurrence of cancer.

133 respondents answered the questionnaire package including both the quantitative quality of life questionnaire (not reported in this paper) and the qualitative questions. Eight respondents missed this latter set of questions. Thus, qualitative analysis was based on 125 participating survivors.

\section{Qualitative analyses of worst and positive experiences and advice for fellow patients Analysis of response length and word frequency}

The length in words of participants' responses was analysed: Women gave the longest answers when asked for positive aspects of their disease with a median of 10.0 words per answer (range 1-24 words), while responses describing the worst experience during cancer disease were shortest with a median of 5.0 words per answer (range 1-43 words). In between was advice for fellow patients (word length median 6.5, range 1-43 words).

In order to identify the most common issues in participants' answers, frequency of each single word was counted electronically. The three most frequent nouns addressing worst experience were "anxiety" $(n=25)$, 
Table 1 Final category system used for the qualitative and quantitative analysis

\begin{tabular}{|c|c|}
\hline Category & Description \\
\hline \multicolumn{2}{|c|}{ Worst experience } \\
\hline $\begin{array}{l}\text { Psychological } \\
\text { distress }\end{array}$ & $\begin{array}{l}\text { Anxiety or uncertainty about the course or outcome of the } \\
\text { illness. }\end{array}$ \\
\hline Chemotherapy & Chemotherapy or related side-effects. \\
\hline Cancer diagnosis & $\begin{array}{l}\text { The shock of receiving cancer diagnosis and the fact of being } \\
\text { a cancer patient. }\end{array}$ \\
\hline Mastectomy & Removal of the breast and the affected body image. \\
\hline Social burden & $\begin{array}{l}\text { Fear of family or other conflicts in partnership or family causec } \\
\text { by the illness. }\end{array}$ \\
\hline $\begin{array}{l}\text { Additional } \\
\text { illnesses }\end{array}$ & $\begin{array}{l}\text { Additional diseases like comorbidities or recurrence during or } \\
\text { after breast cancer. }\end{array}$ \\
\hline Radiotherapy & Radiotherapy with related side-effects. \\
\hline $\begin{array}{l}\text { Endocrine } \\
\text { therapy }\end{array}$ & Endocrine therapy with related side-effects. \\
\hline Nothing & No worst experience. \\
\hline Other & \\
\hline
\end{tabular}

Sample characteristic statements by the women

"uncertainty according to the outcome of surgery"; "uncertainty about the future"; "anxiety"; "fear of recurrence"; "fear of dying"

"chemotherapy"; "loss of hair"; "to look at myself due to the loss of hair" "port implantation for chemotherapy"

"communication of the diagnosis by the gynaecologist"; "Cancer itself! I have always lived a healthy life"; "that you have cancer and can't forget it"

"removal of the breast, loss of self-esteem regarding sexuality"; "losing my breast or dying"; "disfigurement of the body, considerable restrictions in dressing"

"to have to be strong for my family"; "the fear of my twin sister and my daughter"; "that my husband couldn't get along with the changes of my body, what I never had expected"; "to see, how my husband was suffering";

"I had a recurrence"; "cancer disease was accompanied by atrial fibrillations - bad health status for a long time"; "arm pain because my right upper arm was disabled by a fracture"

"loss of energy because of radiation"; "after radiotherapy I had a pneumonia for nearly five years after treatment with cortisone"

"endocrine therapy with all side effects"; "the obligation to take pills continuously despite circulatory complaints"; "my bones, probably affected by the intake of medication"

"pain"; "fatigue"; "that life will never be the same!"; "Everything happened at once. Diagnosis, divorce, driving test, moving house"

\section{Positive aspects}

Change in life priorities

Social support Support by family, fr
help from others.

Good course of The good course and outcome of the illness. cancer

Support by
physicians/ nurses

Gratitude

Other

Advice

Fighting spirit

Think positive, fight, and never lose hope.

Information

Keep calm, get a second opinion, and inform yourself about the illness.

Confidence in Trust your physician and follow his/ her instructions. physicians

Openness

Change of one's own priorities in life in terms of living life more consciously and relaxed, or changes in lifestyle.

The good (medical) treatment by physicians or nurses.

Being grateful to have survived.

Confide in somebody and talk a lot about the illness.

"I think, you live more intensively and consciously"; "I have reconsidered my life, changed several things"; "I see a lot of things more relaxed"; "I have learnt to take more care of myself, to say 'no' more often that makes me proud"

"the experience of intensive and also often unexpected support and friendship"; "my friends never abandoned me"; "l experienced a lot of attention, appreciation and support"; "I met wonderful people"

"tumour was very small"; "no metastases"; "disease was early detected because of annual check-up"

"the experience of caring physicians and nurses"; "advice and reassurance"; "the good medical attendance"

"I have developed a profound feeling of gratitude"; "that I'm still alive"; "looking back on my life and thankfulness"; "regarding every day as a gift from God"

"I could manage my disease very well"

"never give up and think positive all the time"; "always thinking 'Yes, I can manage that!"'; "Never lose hope!"

"inform yourself about all treatment options"; "don't believe just one single physician"; "inform yourself intensively in the internet, get a second opinion"

"do everything the doctor says"; "confidence in physicians"; "adherence to treatment"

"positive conversations, share your experiences"; "talking a lot about the illness"; " "don't hide the disease" 
Table 1 Final category system used for the qualitative and quantitative analysis (Continued)

\begin{tabular}{|c|c|c|}
\hline No advice & It is not possible to give any advice for fellow patients. & $\begin{array}{l}\text { "I can't give any advice"; "none, every patient comes to terms } \\
\text { with it another way" }\end{array}$ \\
\hline $\begin{array}{l}\text { Business as } \\
\text { usual }\end{array}$ & $\begin{array}{l}\text { Don't think too much about the illness, live life in a normal } \\
\text { way. }\end{array}$ & $\begin{array}{l}\text { "fade out disease of daily life, live for the moment"; "master } \\
\text { everyday life as usual, domestic work, sports, friends, theatre"; } \\
\text { "don't think too much about disease, distract yourself, and remain } \\
\text { cheerful" }\end{array}$ \\
\hline $\begin{array}{l}\text { Cancer } \\
\text { screening }\end{array}$ & Have regular cancer screening. & $\begin{array}{l}\text { "go to the doctor in time"; "regular cancer screening"; "early } \\
\text { detection by screening" }\end{array}$ \\
\hline Acceptance & Accept the illness. & "things you can't change you have to accept"; "accepting disease" \\
\hline Self-reflection & Reconsider your life. & $\begin{array}{l}\text { "consider disease as a touchstone and if applicable as turning } \\
\text { point, which is not solely negative but also offers opportunities to } \\
\text { find oneself"; "attend to your own soul, find out, what makes you } \\
\text { happy" }\end{array}$ \\
\hline Belief in God & Strengthening in faith. & "pray a lot"; "don't lose courage, my trust in God helped me a lot" \\
\hline Support group & Visit a support group. & $\begin{array}{l}\text { "contact other patients or a support group"; "visit a support } \\
\text { group as soon as possible" }\end{array}$ \\
\hline Secrecy & Keep your illness as a secret. & "Inform as few people as possible! Hardly anybody can help!" \\
\hline Other & & $\begin{array}{l}\text { "Go to rehab"; "to undergo surgery immediately"; "no } \\
\text { complementary medicine, take part in a trial"; "accept help" }\end{array}$ \\
\hline
\end{tabular}

"chemotherapy" ( $n=25)$, and "diagnosis" $(n=16)$. Asked for positive aspects, women most frequently used words like "life/ living" ( $n=15)$, "illness" $(n=7)$, and "positive" $(n=7)$. When giving advice for fellow patients, the most frequent words were "positive" $(n=23)$, "illness" $(n=18)$, and "physician/s" $(n=12)$.

\section{Interrater agreement}

The median interrater percent agreement between the two raters was $98 \%$ for categories regarding worst experiences, $93 \%$ for positive aspects, and $99 \%$ for advice for fellow patients. To account for random agreements Cohen's kappa was also calculated. The median kappa

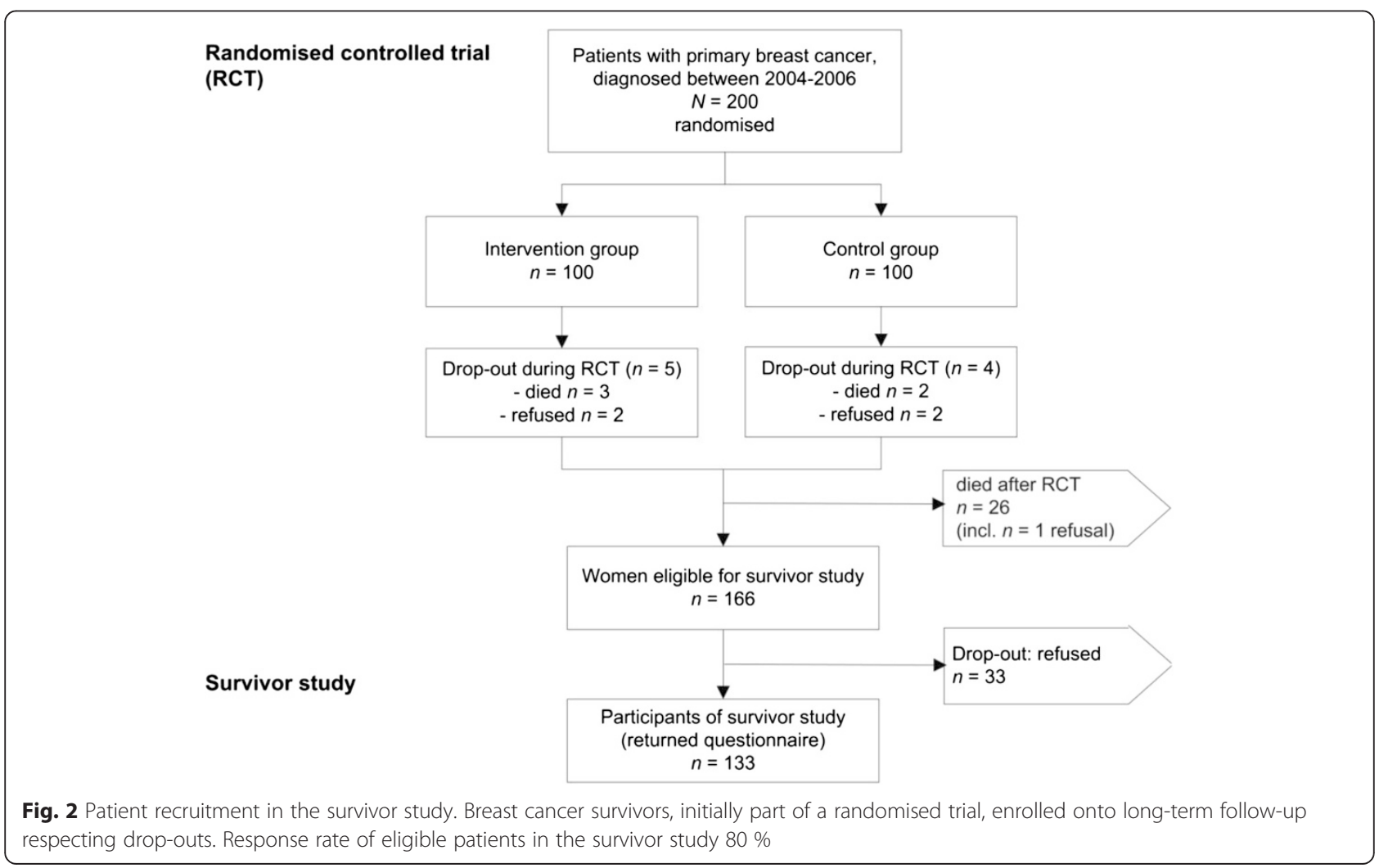


Table 2 Demographic and medical characteristics of patient participants $(n=133)$

\begin{tabular}{cll}
\hline & No. of patients & \% of patients \\
\hline Age (Mean \pm s.d. 64.2 \pm 10.8, range 41-92) & & 8 \\
$<50$ & 45 & 34 \\
$50-59$ & 36 & 27 \\
$60-69$ & 31 & 23 \\
$70-79$ & 13 & 10
\end{tabular}

Months since surgery

(Mean \pm s.d. $84.8 \pm 5.6$, range $74-96$ )

Marital status

$\begin{array}{llr}\text { Married } & 101 & 76 \\ \text { Unmarried } & 4 & 3 \\ \text { Divorced } & 14 & 11 \\ \text { Widowed } & 14 & 11\end{array}$

Children

$\begin{array}{lll}\text { Children } & 113 & 85 \\ \text { No children } & 10 & 8 \\ \text { Unknown } & 10 & 8\end{array}$

Employment status

$\begin{array}{lll}\text { Employed full time } & 20 & 15\end{array}$

$\begin{array}{lll}\text { Employed part time } & 27 & 20\end{array}$

Retired/ not employed $\quad 80 \quad 60$

Unknown $\quad 4 \quad 3$

Educational level

Did not finish school $\quad 2 \quad 2$

Compulsory $\quad 61 \quad 46$

Advanced vocational $\quad 56 \quad 50$

University $\quad 10 \quad 8$

$\begin{array}{lll}\text { Unknown } & 6 & 5\end{array}$

Cancer stage at diagnosis

$\begin{array}{lll}\text { UICC O } & 2 & 2 \\ \text { UICC I } & 68 & 52 \\ \text { UICC II (II a and b) } & 39 & 29 \\ \text { UICC III (III a, b, C) } & 21 & 16 \\ \text { Unknown } & 3 & 2\end{array}$

Surgical procedure

Breast conserving therapy $\quad 106 \quad 80$

$\begin{array}{lll}\text { Mastectomy } & 27 & 20\end{array}$

Treatment (first year after surgery)

Chemotherapy $\quad 94 \quad 71$

$\begin{array}{lll}\text { Radiotherapy } & 118 & 89\end{array}$

Endocrine therapy $\quad 113 \quad 85$

Anti-HER2 monoclonal antibody $\quad 11 \quad 8$

Recurrent cancer

15

s.d. standard deviation 
was 0.83 for worst experiences (range 0.41-0.98), 0.75 for positive aspects (range 0.49-0.95), and 0.95 for advice for fellow patients (range 0.58-1.00) (it should be mentioned that for all three categories the lowest kappa was observed with respect to the response option "other").

\section{Worst experience regarding breast cancer}

Of the 125 survivors answering the qualitative questionnaire, 118 (94\%) responded to the question asking for their worst experience during breast cancer (Table 3). By far the most prominent worst experience was psychological distress, reported by $38 \%$. The category included answers like "uncertainty about the future", "fear of

Table 3 Frequency of breast cancer survivors' answers about their worst experience during breast cancer, positive aspects of the illness and advice for fellow patients

\begin{tabular}{|c|c|c|}
\hline Worst experience $(n=118)$ & No. of patients & $\%$ of patients \\
\hline Psychological distress & 45 & 38 \\
\hline Chemotherapy & 29 & 25 \\
\hline Cancer diagnosis & 21 & 18 \\
\hline Mastectomy & 9 & 8 \\
\hline Social burden & 8 & 7 \\
\hline Additional illness & 7 & 6 \\
\hline Radiotherapy & 3 & 3 \\
\hline Endocrine therapy & 3 & 3 \\
\hline Nothing & 1 & 1 \\
\hline Other & 14 & 12 \\
\hline Positive Aspects ( $n=58)$ & No. of patients & $\%$ of patients \\
\hline Change in life priorities & 29 & 50 \\
\hline Social support & 13 & 22 \\
\hline Good course of cancer & 9 & 16 \\
\hline Support by physicians/ nurses & 6 & 10 \\
\hline Gratitude & 5 & 9 \\
\hline Other & 3 & 5 \\
\hline Advice $(n=110)$ & No. of patients & $\%$ of patients \\
\hline Fighting spirit & 46 & 42 \\
\hline Information & 17 & 16 \\
\hline Confidence in physicians & 12 & 11 \\
\hline Openness & 10 & 9 \\
\hline No advice & 10 & 9 \\
\hline Business as usual & 8 & 7 \\
\hline Cancer screening & 7 & 6 \\
\hline Acceptance & 6 & 6 \\
\hline Self-reflection & 5 & 5 \\
\hline Belief in God & 4 & 4 \\
\hline Support group & 2 & 2 \\
\hline Discreteness & 2 & 2 \\
\hline Other & 9 & 8 \\
\hline
\end{tabular}

recurrence", or "fear of dying". This was followed by chemotherapy with $25 \%$ (e.g. "to look at myself due to the loss of hair", "port implantation for chemotherapy"), and cancer diagnosis with $18 \%$ (e.g. "communication of the diagnosis by the gynaecologist", "Cancer itself! I have always lived a healthy life"). The other defined categories were mentioned by less than $10 \%$ of respondents. $12 \%$ of issues were categorised as other including "pain" which was noted by only two survivors as one of their worst experiences (Table 3). Further examples of answers from individual patients are given in Table 1.

\section{Positive aspects of cancer}

When asked if there had been also positive aspects of the disease, about half of the survivors affirmed this question (positive aspects: "yes" 60/125 (48 \%); “no": 54/125 (43\%); "missing" 11/125 (9\%)). Of those 60, 58 women gave written information about their most positive experience (Table 3). A change in life priorities was reported by $50 \%$. For example a woman answered "I have reconsidered my life, changed several things" and another described "I have learnt to take more care of myself, to say 'no' more often that makes me proud". Furthermore $22 \%$ of survivors mentioned the role of social support by family, friends, and colleagues (e.g. "the experience of intensive and also often unexpected friendship", "my friends never abandoned me"). $16 \%$ named the good course of cancer (e.g. "tumour was very small", "no metastases") and $10 \%$ emphasised (medical) support by physicians and nurses (e.g. "the experience of caring physicians and nurses", "the good medical attendance"). The remaining categories gratitude and other were used by less than $10 \%$ (see Tables 1 and 3).

\section{Advice for fellow patients}

This question was answered by 110 out of 125 women (88\%, Table 3). By far the most frequent advice for newly diagnosed patients was fighting spirit with $42 \%$. In this regard a woman recommended "never give up and think positive all the time" and another one advised "Never lose hope!". Furthermore, $16 \%$ of survivors suggested information, for example "inform yourself intensively in the internet, get a second opinion" or "don't believe just one single physician". Another $11 \%$ advised confidence in physicians. (e.g. "do everything the doctor says"). Other categories were used by less than $10 \%$ (see Tables 1 and 3).

\section{Evaluation of physicians}

Of the 50 physicians contacted for the survivor survey, one was retired and could not be reached by mail. Of the remaining 49 doctors, 29 participated in the survey (59\%). Those had a mean age of 53.8 years (s.d. \pm 9.0), were predominantly female $(62 \%)$ and all but one 
worked as gynecologist with length of professional experience in treating patients with breast cancer from 6 to 46 years (Median 23.5) (see Table 4). Four of the 29 participants did not fill in the questionnaire appropriately so their answers could not be analysed.

Overall, physicians' estimates of the frequency of women's experiences corresponded relatively well with their patients' actual answers (Table 5). Regarding women's worst experience during breast cancer, doctors and survivors named the same three issues most frequently (cancer diagnosis, chemotherapy, psychological distress). However, physicians underestimated the role of psychological distress. This was by far the most frequent answer of survivors (38\%), but was rated as the most common answer by only $16 \%$ of physicians. Instead, $60 \%$ of doctors thought that cancer diagnosis was the worst experience for patients (true answer $18 \%$ ).

Table 4 Characteristics of participating physicians $(n=29)$

\begin{tabular}{|c|c|c|}
\hline & $\begin{array}{l}\text { No. of } \\
\text { physicians }\end{array}$ & $\begin{array}{l}\% \text { of } \\
\text { physicians }\end{array}$ \\
\hline \multicolumn{3}{|l|}{$\begin{array}{l}\text { Age (Mean } \pm \text { s.d. } 53.8 \pm 9.0, \\
\text { range } 35-72)\end{array}$} \\
\hline$<40$ & 1 & 4 \\
\hline $40-49$ & 8 & 29 \\
\hline $50-59$ & 12 & 43 \\
\hline $60-69$ & 6 & 21 \\
\hline $70+$ & 1 & 4 \\
\hline \multicolumn{3}{|l|}{ Sex } \\
\hline Female & 18 & 62 \\
\hline Male & 11 & 38 \\
\hline \multicolumn{3}{|l|}{ Specialisation } \\
\hline Gynaecologist & 28 & 97 \\
\hline General practitioner & 1 & 3 \\
\hline \multicolumn{3}{|l|}{ Professional experience } \\
\hline \multicolumn{3}{|c|}{$\begin{array}{l}\text { Breast cancer patients per year } \\
\text { (Median 30.0, range 10-700) }\end{array}$} \\
\hline$<20$ & 8 & 28 \\
\hline $20-50$ & 13 & 45 \\
\hline $51-100$ & 2 & 7 \\
\hline $101-199$ & 4 & 14 \\
\hline $200+$ & 2 & 7 \\
\hline \multicolumn{3}{|c|}{$\begin{array}{l}\text { Years treating breast cancer patients } \\
\text { (Median 23.5, range 6-46) }\end{array}$} \\
\hline$<10$ & 2 & 7 \\
\hline $10-19$ & 8 & 29 \\
\hline $20-29$ & 11 & 39 \\
\hline $30-39$ & 6 & 21 \\
\hline $40+$ & 1 & 4 \\
\hline
\end{tabular}

s.d. standard deviation
Regarding positive aspects of cancer disease, physicians also showed a good correspondence with their patients, naming the issues in nearly the same order as the survivors (Table 5). They only underestimated the role of support by physicians and nurses. While $10 \%$ of survivors reported this issue as their most positive experience during the illness, $52 \%$ of doctors thought it would be the rarest answer given by patients.

When asked which advice breast cancer survivors might give to newly diagnosed patients, physicians (44\%) and survivors (42\%) similarly named fighting spirit most frequently. Seeking information about the illness was also frequently named by doctors $(21 \%)$ and women (16\%), while the role of openness was overestimated by physicians $(28 \%)$ compared with patients (9\%).

\section{Discussion}

The subject of survivorship is of increasing interest due to the improved methods of cancer screening and therapy that prolong survival. The present study investigated how breast cancer patients remembered their illness episode about seven years after therapy onset. We are aware that such retrospective reports are vulnerable to distortions, such as recall and hindsight bias [36], reframing [37], and response shift [38, 39]. Different factors may contribute to recall bias [40] such as mood [41], the kind of material to be remembered (i.e. information in great detail) [42], or personal characteristics (i.e. optimism [43]). So, we deliberately bypassed the issue of "objectivity" and memory distortions, instead focusing on subjective recollections because these are the kinds of opinions and experiences that are communicated by survivors and shape the perceived stereotypes of breast cancer via their families, friends, and the media. These stories and stereotypes will in turn influence future generations of patients [21].

To our knowledge this is the only study investigating the perspective of breast cancer survivors regarding their course of illness which is also supplemented by the perspective of their physicians. The methodology we have used can act as a paradigm for others to investigate these issues. Open-ended, qualitative surveys go well beyond standardised assessment of quality of life and elicit new information. In contrast a recent study by Hollen et al. [44] investigated the importance of quality of life issues that are listed by breast cancer patients in general without assessing their subjective experiences in their course of treatment and recovery.

Before discussing our results, the strengths and limitations of the present study should be considered. The study population was well-defined due to patients' participation in an earlier randomised trial [23]. The response rate was high given that the study was conducted 
Table 5 Physicians' estimates of patients' most frequent answers $(n=25)$

\begin{tabular}{llll}
\hline & \multicolumn{2}{l}{ Physicians'responses } & $\begin{array}{l}\text { Patients' } \\
\text { responses }\end{array}$ \\
\hline Worst experience & 1.8 & $\%$ & $\%^{\mathrm{a}}$ \\
Cancer diagnosis & 2.5 & 60 & 18 \\
Chemotherapy & 2.9 & 24 & 25 \\
Psychological distress & 3.4 & 16 & 38 \\
Social burden & 4.1 & - & 7 \\
Mastectomy & Mean & $\%$ & 8 \\
Positive aspects & 2.1 & 52 & 50 \\
Change in life priorities & 2.5 & 24 & 22 \\
Social support & 3.0 & 16 & 16 \\
Good course of cancer & 3.2 & 8 & 9 \\
Gratitude & 4.1 & - & 10 \\
Support by physicians & Mean & $\%$ & $\%^{\mathrm{a}}$ \\
Advice & 2.2 & 44 & 42 \\
Fighting spirit & 2.3 & 28 & 9 \\
Openness & 2.8 & 21 & 16 \\
Information & 3.3 & 8 & 11 \\
Confidence in physicians/ nurses & 4.1 & 4 & 7 \\
Business as usual & (1) & & \\
\hline
\end{tabular}

apercentages based on raw counts of patients' most frequent answers (multiple answers were possible, see Table 3); Mean = mean of ranks on a scale of 1-5; \%: percentage of physicians rating the category as "most frequent answer" (response category "1" on a scale of 1-5)

more than six years after diagnosis (80\%). Furthermore, this investigation has high external validity (no exclusion according to age, stage, or recurrence, participants from both urban and rural areas). Further strengths are the emergent rather than predefined categories and the use of duplicate assessors to define the categories from the data.

However, there are also some limitations: First, we used a mailed survey instead of semi-structured interviews or focus group meetings. Therefore, most of the qualitative answers were short and enquiry for further explanation was not possible. The reason to choose this method anyhow was that our participants were already familiar with the questionnaire method. A mailed survey has also the advantage that there is less likelihood of social desirability than in interviews, no potential influence of the interviewer, and the accessibility of a larger sample of participants. Another limitation is the response rate of only $59 \%$ in the physician survey. It is possible that only those doctors who have a particularly close relationship with their patients participated, so that the observed patientphysician agreement might be overestimated. Third, although this study can claim external validity for breast cancer patients in Germany, future studies need to confirm results in other countries and healthcare settings.
In qualitative research each category will contain a range of different perspectives. In order to address this problem we tried to be as objective and data-driven as possible when analysing patients' qualitative statements. We therefore used word counting to identify objectively the most frequent issues in participants' answers. In addition, two raters categorised the data independently. Nonetheless, we are aware that there is never a sole truth [45].

Keeping these pros and cons in mind, one key result is that the major part of our breast cancer survivors remembered psychological distress (such as fear of recurrence or uncertainty about the future) as their worst experience. A possible explanation might be the high prevalence of fear of recurrence which has been shown in long-term breast cancer survivors [11]. Thus, uncertainty and fear are still relevant to survivors so that these psychological complaints are also remembered as particularly burdensome during the illness. This information is directly relevant to physicians, who should anticipate psychological distress in their patients during the whole follow-up period and encourage patients to express their fears so that these can be discussed. Good patient-physician communication may help to reduce these fears and uncertainties and improve patient satisfaction [46] in order to prevent chronic psychological distress in long-term survivors [47].

In addition, chemotherapy was reported by one out of four women as particularly burdensome during the illness. These medical side effects have been already shown to be common psychosocial concerns in women with a recent diagnosis of breast cancer [48] and also remain one of the most burdensome experiences remembered by long-term survivors. Specific complaints of individual breast cancer patients need to get more attention during the time of medical treatment and follow-up. One solution to this problem is the regular assessment of the patient's quality of life. These results need to be communicated to the physician with recommendations for tailored treatment of reduced quality of life [26]. This kind of intervention has been demonstrated to be effective for breast cancer patients during the first year of medical follow-up [23].

Another interesting result is that somatic symptoms seemed to play little or no role in the patients' recollection of their illness. In particular, the concern over "pain" widely debated in oncology was almost never mentioned by patients in our survivor study. This information might help newly diagnosed breast cancer patients by taking away some of their fears.

Apart from this about half of the participants also reported positive effects related to the illness. This is notably lower than the percentage found by Sears et al. [49] with $83 \%$ of breast cancer patients reporting at least 
one benefit in their disease. An explanation for these divergent results might be that Sears et al. surveyed recently diagnosed women whereas the present study focused on the perspective of long-term survivors. Perhaps finding benefit in the disease is especially important during the time of diagnosis as a form of coping. But in the long run it can be also maladaptive if expectations of benefits are not realised [50]. Similarly, Foley et al. [22] noticed that most cancer survivors experienced no impact of the disease on their lives.

Of those women in our sample who reported positive aspects most emphasised a change in life priorities. This is closely related to the concept of 'posttraumatic growth' - personally important changes as a result of a life-threatening crisis - often described in relation to cancer survivorship [51]. Similarly, a substantial number of survivors in our sample mentioned that they are living more intensively and consciously.

Furthermore, women evaluated the social support they received during the illness as a positive aspect. Although some survivors reported the social burden caused by cancer (fear of family members, conflicts in partnership) as their worst experience, a considerable number of the women experienced positive social support by family, friends, and colleagues. This seems to be an important aspect of coping with the illness, as it has been demonstrated that social support is a significant predictor for a better long-term quality of life in breast cancer patients [6]. Likewise, Sears et al. [49] identified the topic of social relationships as the most frequent benefit reported by recently diagnosed breast cancer patients. Similarly, social support was also relevant for survivors in the present study but not as important as a change in life priorities. Perhaps the meaning of positive experiences changes during the course of the disease. Whereas social support is most helpful in the acute phase of the illness its role becomes less important during survivorship. Instead, personal changes are more relevant because they are long-lasting and therefore can be still noticed as a benefit in long-term survivors. This needs to be investigated in future prospective studies.

Support by physicians and nurses was also stressed as a positive aspect during cancer. Medical staff need to be aware that they are an important aid for their patients in coping with breast cancer. This information relates to studies investigating patient-physician communication. Those identified that breast cancer patients perceive a caring attitude of the physician as more important than information-giving [52]. Likewise, physician attentiveness and empathy have been found to be associated with greater patient satisfaction and reduced emotional distress after the consultation in cancer patients [53]. In this sense the present study supports the assumed high relevance of patient-physician communication by demonstrating that a positive relationship with physicians and nurses is still important in the recollection of long-term survivors.

Survivors who reported positive aspects of their disease were also more likely to give advice to fellow patients compared to those women who did not remember any positive aspects. The vast majority recommended to think positive, to fight, and to never give up. This kind of fighting spirit has been found to be associated with better psychological adjustment to advanced breast cancer $[54,55]$. Additionally, previous studies identified a positive relationship between trait optimism and wellbeing in breast cancer patients during the course of medical therapy $[8,56]$ and long-term follow-up [57]. The second most common advice was to inform oneself intensively about the illness e.g. by using the internet or by getting a second opinion. The specific information needs of cancer patients have been described in a systematic review including 112 articles published between 1980 and 2003 [58]. Reasons why some cancer patients do not want to get further information were qualitatively analysed by Leydon et al. [59] conducting in depth interviews with 17 cancer patients. They identified three motivations: hope (keeping away fearful, contradictory, or negative information to preserve hope), charity (concerns about taking up too much time of the doctor to the detriment of other patients), and faith (the doctor knows best, medical knowledge is too complex to understand). In agreement with the last explanation, some women in our sample adopted a passive posture by recommending confidence in physicians (do anything the doctor says, faith in physicians and medical therapy).

The study also demonstrated good but not perfect correspondence between physicians and patients. This is in contrast to the bulk of previous studies [60,61]. There may be two explanations for this finding: (1) the measurement method, asking for direct experiences instead of standardised questionnaires and (2) the close relationship of our physicians with their patients as a result of regular follow-up, which might have been intensified by the randomised trial [62]. Physicians realised the affective dimension of the worst experience by choosing cancer diagnosis first $(60 \%)$ and psychological distress third (16\%). Patients had a similar opinion, although the two issues were reversed in frequency. Patients and physicians agreed that psychological distress and cancer diagnosis were particularly important elements of the cancer experience in the follow-up. The important lesson for physicians to learn is that distress caused by fear of recurrence or uncertainty about the future probably plays a more important role in the follow-up phase compared to the shock of diagnosis. So, in the medical encounter patients' fears need to be addressed repeatedly, also discussing prognosis and the risk of recurrence. Another finding was that doctors tended to 
underestimate the important role they played for their patients: they need to be more aware of how much patients appreciate their medical and interpersonal support as an important aid in coping with their disease.

\section{Conclusions}

This is the first study investigating the recollection of breast cancer survivors regarding their course of illness which is supplemented by the perspective of their physicians. Results demonstrated that physicians had a good overall understanding of the subjective experiences of breast cancer patients. Most survivors remembered psychological distress as their worst experience during breast cancer, followed by chemotherapy. These issues need to be considered even more in patient care. Physicians should address patients' fears repeatedly in the medical encounter. Regular assessments of patients' quality of life during medical follow-up can help to identify these specific complaints but should also include recommendations for the physician for targeted psychosocial and medical support. About half of the survivors also reported positive aspects of the illness, such as a change in life priorities. Their most frequent advice was fighting spirit. These advices and positive aspects of the disease should be further investigated to promote positive ways of coping with the illness.

Investigating the perspective of cancer survivors in this way is important since subjective recollections of former patients shape communication about the illness in everyday life, usage and acceptance of health care and ultimately, the expectations of new generations of patients.

\section{Competing interests}

The authors declare that they have no competing interests.

\section{Authors' contributions}

All authors contributed to the conception of the study design. PL, BS, and MKS have made substantial contribution to the acquisition of data. PL, MK, $\mathrm{BS}, \mathrm{WL}, \mathrm{JW}$, and MKS have made substantial contribution to the analysis and interpretation of data. PL drafted the manuscript. MK, BS, WL, JW, El, and MKS have made substantial contributions to the revision of the manuscript for important intellectual content. All authors have approved the submitted manuscript and agreed to be accountable for all aspects of the work. Sadly, WL died when working on this project.

\section{Acknowledgements}

This work was supported by the Deutsche Krebshilfe, Project number 109216. The authors would like to appreciate all women who participated in the survivor study and took the time and effort to remember the course of their breast cancer disease. Furthermore, we would like to thank the physicians who took part in the survey.

\footnotetext{
Author details

'Tumor Center Regensburg e.V., An-Institute of the University of Regensburg, Regensburg, Germany. ${ }^{2}$ Center for Clinical Trials, University Hospital Regensburg, Regensburg, Germany. ${ }^{3}$ Leeds Institute of Health Sciences, University of Leeds, Leeds, UK. ${ }^{4}$ Department of Gynecology and Obstetrics, University Medical Center Regensburg, Regensburg, Germany.
}

Received: 30 October 2014 Accepted: 21 July 2015

Published online: 29 July 2015

\section{References}

1. Dorval M, Maunsell E, Deschênes L, Brisson J, Mâsse B. Long term quality of life after breast cancer: comparison of 8-year survivors with population controls. J Clin Oncol. 1998;16:487-94.

2. Ganz PA, Rowland JH, Desmond KA, Meyerowitz BE, Wyatt GE. Quality of life in long-term, disease-free survivors of breast cancer: a follow-up study. J Natl Cancer Inst. 2002;54:39-49.

3. Bloom JR, Stewart SL, Chang S, Banks PJ. Then and now: quality of life of young breast cancer survivors. Psychooncology. 2004;13:147-60.

4. Carver CS, Smith RG, Petronis VM, Antoni MH. Quality of life among longterm survivors of breast cancer: different types of antecedents predict different classes of outcomes. Psychooncology. 2006;15:749-58.

5. Ahn SA, Park BW, Noh DY, Nam SJ, Lee ES, Kim SH, et al. Health related quality of life in disease-free survivors of breast cancer with the general population. Ann Oncol. 2007;18:173-82.

6. King MT, Kenny P, Shiell A, Hall J, Boyages J. Quality of life three months and one year after first treatment for early stage breast cancer: influence of treatment and patient characteristics. Qual Life Res. 2000;9:789-800.

7. Helgeson V, Snyder P, Seltman H. Psychological and physical adjustment to breast cancer over 4 years: identifying distinct trajectories of change. Health Psychol. 2004;23:3-15.

8. Schou I, Ekeberg $\varnothing$, Sandvik L, Hjermstad M, Ruland C. Multiple predictors of health-related quality of life in early stage breast cancer. Data from a year follow-up study compared with the general population. Qual Life Res. 2005;14:1813-23.

9. Härtl K, Engel J, Herschbach P, Sommer H, Friese K. Personality traits and psychological stress: quality of life over 2 years following breast cancer diagnosis and psychological impact factors. Psychooncology. 2010;19:160-9.

10. Thewes T, Butow P, Girgis A, Pendlebury S. The psychosocial needs of breast cancer survivors; a qualitative study of the shared and unique needs of younger versus older survivors. Psychooncology. 2004;13:177-89.

11. Koch L, Bertram H, Eberle A, Holleczeck B, Schmid-Höpfner S, Waldmann A, et al. Fear of recurrence in long-term breast cancer survivors - still an issue. Results on prevalence, determinants, and the association with quality of life and depression from the Cancer Survivorship - a multi-regional populationbased study. Psychooncology. 2014;23:547-54.

12. Mols F, Vingerhoets A, Coebergh JW, van de Poll-Franse L. Quality of life among long-term breast cancer survivors: a systematic review. Eur J Cancer. 2005;41:2613-9.

13. Hoffman CJ, Ersser SJ, Hopkinson JB, Nicholls PG, Harrington JE, Thomas PW. Effectiveness of mindfulness-based stress reduction in mood, breast- and endocrine-related quality of life, and well-being in stage 0 to III breast cancer: a randomized, controlled trial. J Clin Oncol. 2012;30:1335-42.

14. Hayes SC, Rye S, DiSipio T, Yates P, Bashford J, Pyke C, et al. Exercise for health: a randomized, controlled trial evaluating the impact of a pragmatic, translational exercise intervention on the quality of life, function and treatment-related side effects following breast cancer. Breast Cancer Res Treat. 2013;137:175-86.

15. Naumann F, Munro A, Martin E, Magrani P, Buchan J, Smith C, et al. An individual-based versus group-based exercise and counselling intervention for improving quality of life in breast cancer survivors. A feasibility and efficacy study. Psychooncology. 2012;21:1136-9.

16. Jafari N, Zamani A, Farajzadegan Z, Bahrami F, Emami H, Loghmani A. The effect of spiritual therapy for improving the quality of life of women with breast cancer: a randomized controlled trial. Psychol Health Med. 2013;18:56-69.

17. Aaronson NK, Ahmedzai S, Bergman B, Bullinger M, Cull A, Duez NJ, et al. The European Organization for Research and Treatment of Cancer QLQ-C30: a quality-of-life instrument for use in international clinical trials in oncology. J Natl Cancer Inst. 1993;85:365-76.

18. Cella D, Tulsky D, Gray G, Sarfian B, Lloyd S, Linn E, et al. The Functional Assessment of Cancer Therapy Scale: development and validation of the general measure. J Clin Oncol. 1993;11:570-9.

19. Tishelman C, Lövgren M, Broberger E, Hamberg K, Sprangers M. Are the most distressing concerns of patients with inoperable lung cancer adequately assessed? A mixed-methods analysis. J Clin Oncol. 2010;28:1942-9.

20. Lauver D, Connolly-Nelson K, Vang P. Stressors and coping strategies among female cancer survivors after treatments. Cancer Nurs. 2007;30:101-11.

21. Hertrampf K, Wenz H, Lehmann K, Lorenz W, Koller M. Quality of life of patients with maxillofacial defects after treatment for malignancy. Int J Prosthodont. 2004;17:657-65. 
22. Foley $K L$, Farmer D, Petronis $V$, Smith R, McGraw S, Smith K, et al. A qualitative exploration of the cancer experience among long-term survivors: comparison by cancer type, ethnicity, gender, and age. Psychooncology. 2006;14:248-58

23. Klinkhammer-Schalke M, Koller M, Steinger B, Ehret C, Ernst B, Wyatt JC, et al. Direct improvement of quality of life using a tailored quality of life diagnosis and therapy approach: randomised trial in 200 women with breast cancer. Br J Cancer. 2012;106:826-38.

24. Rothwell PM. External validity of randomised controlled trials: "To whom do the results of this trial apply?". Lancet. 2005;365:82-93.

25. Koller M, Klinkhammer-Schalke M, Ehret C, Steinger B, Ernst B, Hofstädter L, et al. Diagnostik und Therapie der krankheitsbezogenen Lebensqualität bei Patientinnen mit Mammakarzinom. Protokoll einer randomisierten klinischen Studie am Tumorzentrum Regensburg. ZEFQ. 2006;100:175-82.

26. Klinkhammer-Schalke M, Koller M, Wyatt J, Steinger B, Ehret C, Ernst B, et al. Quality of life diagnosis and therapy as complex intervention for improvement of health in breast cancer patients: delineating the conceptual, methodological, and logistic requirements (modeling). Langenbecks Arch Surg. 2008;393:1-12.

27. Klinkhammer-Schalke M, Koller M, Steinger B, Ehret C, Ernst B, Wyatt J, et al. Implementing a system of quality of life diagnosis and therapy for breast cancer patients: Results of an exploratory trial as prerequisite for a subsequent RCT. Br J Cancer. 2008;99:415-22.

28. Howlader N, Noone AM, Krapcho M, Garshell J, Miller D, Altekruse SF, et al. SEER Cancer Statistics Review, 1975-2011, National Cancer Institute [http:// seer.cancer.gov/csr/1975_2011/].

29. Robert Koch-Institut und die Gesellschaft der epidemiologischen Krebsregister in Deutschland e.V. Krebs in Deutschland 2009/2010. 9th ed. Berlin: ruksaldruck; 2013.

30. Campbell M, Fitzpatrick R, Haines A, Kinmonth A, Sandercock P, Spiegelhalter D, et al. Framework for design and evaluation of complex interventions to improve health. BMJ. 2000;321:694-6.

31. Edwards PJ, Roberts I, Clarke MJ, DiGuiseppi C, Wentz R, Kwan I, et al. Methods to increase response to postal and electronic questionnaires (review). The Cochrane Collaboration 2009, 3:doi: 10.1002/ 14651858.MR000008.pub4.

32. Dey I. Qualitative Data Analysis. London: Routledge; 1993.

33. Pennebaker J, Francis M, Booth R. Linguistic Inquiry and Word Count (LIWC): LIWC2001. Mahwah, NJ: Lawrence Erlbaum; 2001.

34. Malterud K. Qualitative research: standards, challenges, and guidelines. Lancet. 2001;358:483-8.

35. Pope C, Ziebland S, Mays N. Qualitative research in health care: analysing qualitative data. BMJ. 2000;320:114-6.

36. Kahneman D, Slovic P, Tversky A. Judgment Under Uncertainty: Heuristics and Biases. Cambridge, UK: Carrbridge University Press; 1982.

37. Bernhard J, Hürny C, Maibach R, Herrmann R, Laffer U. Quality of life as a subjective experience: reframing of perception in patients with colon cancer undergoing radical resection with or without adjuvant chemotherapy. Ann Oncol. 1999;10:775-82.

38. Breetvelt IS, Van Dam FS. Underreporting by cancer patients: the case of response-shift. Soc Sci Med. 1991;32:981-7.

39. Sprangers M, Schwartz C. Integrating response shift into health-related quality of life research: a theortical model. Soc Sci Med. 1999;48:1507-15.

40. Coughlin S. Recall bias in epidemiologic studies. J Clin Epidemiol. 1990;43:87-91.

41. Bradley B, Mogg K. Mood and personality in recall of positive and negative information. Behav Res Ther. 1994;32:137-41.

42. Berney LR, Blane DB. Collecting retrospective data: accuracy of recall after 50 years judged against historical records. Soc Sci Med. 1997:45:1519-25.

43. Abele A, Gendolla G. Individual differences in optimism predict the recall of personally relevant information. Personal Individ Differ. 2007;43:1125-35.

44. Hollen PJ, Msaouel P, Gralla RJ. Determining issues of importance for the evaluation of quality of life and patient-reported outcomes in breast cancer: results of a survey of 1072 patients. Breast Cancer Res Treat. 2015. doi:10.1007/s10549-015-3420-5.

45. Mays N, Pope C. Qualitative research in health care. Assessing quality in qualitative research. BMJ. 2000;320:50-2.

46. Valderas JM, Kotzeva A, Espallargues M, Guyatt G, Ferrans CE, Halyard MY, et al. The impact of measuring patient-reported outcomes in clinical practice: a systematic review of the literature. Qual Life Res. 2008;17:179-93.
47. Lam W, Ting Shin Y, Bonanno G, Mancini A, Fielding R. Distress trajectories at the first year diagnosis of breast cancer in relation to 6 years survivorship. Psychooncology. 2012;21:90-9.

48. Beatty L, Oxlad M, Koczwara B, Wade T. The psychosocial concerns and needs of women recently diagnosed with breast cancer: a qualitative study of patient, nurse and volunteer perspectives. Health Expect. 2008;11:331-42.

49. Sears S, Stanton A, Danoff-Burg S. The yellow brick road and the Emerald City: benefit finding, positive reappraisal coping and posttraumatic growth in women with early stage breast cancer. Health Psychol. 2003;22:487-97.

50. Tomich P, Helgeson V. Is finding something good in the bad always good? Benefit finding among women with breast cancer. Health Psychol. 2004;23:16-23.

51. Tedeschi R, Calhoun L. The posttraumatic growth inventory: measuring the positive legacy of trauma. J Trauma Stress. 1996;9:455-71.

52. Roberts C, Cox C, Reintgen D, Baile W, Gibertini M. Influence of physician communiciation on newly diagnosed breast patients' psychologic adjustment and decision-making. Cancer. 1994;74:336-41.

53. Zachariae R, Pedersen CG, Jensen AB, Ehrnrooth E, Rossen PB, von der Maase $\mathrm{H}$. Association of perceived physician communication style with patient satisfaction, distress, cancer-related self-efficacy, and perceived control over the disease. Br J Cancer. 2003;88:658-65.

54. Classen C, Koopman C, Angell K, Spiegel D. Coping styles associated with psychological adjustment to advanced breast cancer. Health Psychol. 1996;16:434-7.

55. Stewart DE, Cheung AM, Duff S, Wong F, McQuestion M, Cheng T, et al. Attributions of cause and recurrence in long-term breast cancer survivors. Psychooncology. 2001;10:179-83.

56. Metthews E, Cook P. Relationships among optimism, well-being, selftranscendence, coping, and social support in women during treatment for breast cancer. Psychooncology. 2009;18:716-26.

57. Carver S, Smith R, Derhagopian R, Antoni M, Petronis V, Weiss S. Optimistic personality and psychosocial wellbeing during treatment predict psychosocial well-being among long-term survivors of breast cancer. Health Psychol. 2005;24:508-16.

58. Rutten L, Arora N, Bakos A, Aziz N, Rowland J. Information needs and sources of information among cancer patients: a systematic review of research (1980-2003). Patient Educ Couns. 2005;57:250-61.

59. Leydon G, Boulton M, Moynihan C, Jones A, Mossman J, Boudioni M, et al. Cancer patients' information needs and information seeking behavior: in depth interview study. BMJ. 2000;320:909-13.

60. Suarez-Almazor M, Conner-Spady B, Kendall C, Russell A, Skeith K. Lack of congruence in the ratings of patients' health status by patients and their physicians. Med Decis Making. 2001;21:113-21.

61. Street $R$, Haidet $P$. How well do doctors know their patients? Factors affecting physician understanding of patients' health beliefs. J Gen Intern Med. 2010;26:21-7.

62. Anderson L, Zimmerman M. Patient and physician perceptions of their relationship and patient satisfaction: a study of chronic disease management. Patient Educ Couns. 1993;20:27-36.

\section{Submit your next manuscript to BioMed Central and take full advantage of:}

- Convenient online submission

- Thorough peer review

- No space constraints or color figure charges

- Immediate publication on acceptance

- Inclusion in PubMed, CAS, Scopus and Google Scholar

- Research which is freely available for redistribution 